\title{
Presenting complaints and mortality in a cohort of 22000 adult emergency patients at a local hospital in Nepal
}

\author{
Samita Giri1 ${ }^{1,2,3}$, Tormod Rogne ${ }^{1,4}$, Oddvar \\ Uleberg $^{1,5}$, Eva Skovlund ${ }^{6}$, Sanu Krishna \\ Shrestha ${ }^{7}$, Rajendra Koju ${ }^{8}$, Jan Kristian \\ Damås $^{4,9,10}$, Erik Solligård ${ }^{1,4,10}$, Kari R \\ Risnes $^{3,11}$ \\ ${ }^{1}$ Department of Circulation and Medical Imaging, \\ Norwegian University of Science and Technology, \\ Trondheim, Norway \\ ${ }^{2}$ Department of Community Programs, Dhulikhel \\ Hospital, Kathmandu University Hospital, Dhulikhel, \\ Nepal \\ ${ }^{3}$ Department of Clinical and Molecular Medicine, \\ Norwegian University of Science and Technology, \\ Trondheim, Norway \\ ${ }^{4}$ Gemini Center for Sepsis Research, St. Olav's hospital, \\ Trondheim University Hospital, Trondheim, Norway \\ ${ }^{5}$ Department of Emergency Medicine and Pre-Hospital \\ Services, St. Olav's Hospital Trondheim University \\ Hospital, Trondheim, Norway \\ ${ }^{6}$ Department of Public Health and Nursing, Norwegian \\ University of Science and Technology, NTNU, \\ Trondheim, Norway \\ ${ }^{7}$ Department of Emergency, Dhulikhel Hospital, \\ Kathmandu University Hospital, Dhulikhel, Nepal \\ ${ }^{8}$ Department of Internal Medicine, Dhulikhel Hospital, \\ Kathmandu University Hospital, Dhulikhel, Nepal \\ ${ }^{9}$ Department of Infectious Diseases, St. Olav's Hospital, \\ Trondheim University Hospital, Trondheim, Norway \\ ${ }^{10}$ Clinic of Anesthesia and Intensive Care, St. Olav's \\ hospital, Trondheim University Hospital, Trondheim, \\ Norway \\ ${ }^{11}$ Childrens Clinic, St. Olav's Hospital, Trondheim \\ University Hospital, Trondheim, Norway
}

\section{Correspondence to:}

Kari Risnes

Department of Clinical and Molecular Medicine Norwegian University of Science and Technology PO BOX 8905

NO-7491

Trondheim

Norway

kari.risnes@ntnu.no
Background There is a need to develop sustainable emergency health care systems in low-resource settings, but data that analyses emergency health care needs in these settings are scarce. We aimed at assessing presenting complaints (PCs) and post-discharge mortality in a large emergency department population in Nepal.

Methods Characteristics of adult patients who entered the emergency department (ED) in a hospital in Nepal were prospectively recorded in the local emergency registry from September 2013 until December 2016. To assess post-ED mortality, patient households were followed-up by telephone interviews at 90 days.

Results In 21892 included adults, the major PC categories were injuries (29\%), abdominal complaints (23\%), and infections (16\%). Median age was 40 years and sex distribution was balanced. Among 3793 patients followed at 90 days, $8 \%$ had died. For respiratory and cardiovascular PCs, 90-days mortality were $25 \%$ and $23 \%$. The highest mortality was in individuals with known chronic lung disease, in this group $32 \%$ had died by 90 days of ED discharge, regardless of PC. In women, illiteracy compared to literacy (adjusted odds ratio $(\mathrm{aOR})=7.0,95 \%$ confidence interval $(\mathrm{CI})=2.1-23.6)$ and being both exposed to tobacco-smoking and traditional cooking stove compared to no smoke $(\mathrm{aOR}=2.8$, 95\% $\mathrm{CI}=1.6-4.9)$ were associated with mortality. The mortality was much higher among family-initiated discharged patients $(17 \%, \mathrm{aOR}=5.4,95 \% \mathrm{CI}=3.3-8.9) \mathrm{com}-$ pared to doctor-initiated discharged (3\%).

Conclusions Our report suggests that nearly one in ten patients seeking emergency health care died within 90 days. This finding is alarming and novel. Post-discharge studies need to be replicated and appropriate follow-up programs in low-resource settings where primary health care is underdeveloped are urgently needed.

The Disease Control Priorities project has estimated that almost half of the deaths and over a third of the disabilities in low- and middle-income countries (LMICs) could be addressed through effective emergency care [1]. Top priority to emergency care has been recognized by the World Health Assembly [2]. A recent study reported that death rates and disability-adjusted life-years (DALYs) attribut- 
able to emergency conditions are three times higher in low-income countries (LICs) than high-income countries (HICs) [3]. Nevertheless, emergency health services are still underfunded and underdeveloped in LMICs [4], and it has been argued that improvement is particularly needed in emergency care systems $[1,5]$. However, a recent systematic review of emergency care in 59 LMICs has pinpointed the scarcity of relevant data that makes clinical and policy priorities difficult [6]. Another systematic review performed in 139 LMICs showed that patient outcomes from emergency care were poorly reported. There were 3-4 times more studies reporting mortality during emergency care compared to reporting outcomes after emergency discharge [7].

In Nepal, emergency care systems are underdeveloped [8,9]. Patients often directly access emergency care irrespective of the type of health complaints, and primary care physicians in emergency department (ED) are often the first contact point with healthcare. Previous studies from Nepal have focused on certain groups of emergency patients such as injuries and infections, and reported that patient volumes have increased in recent years [10-12]. A systematic review among traffic injuries in Nepal reported that the mortality rate had almost doubled from 2001 to 2013 [13], and that the burden of non-communicable diseases (NCDs) had almost doubled $[14,15]$. These reports, however, provide only fragments of the picture of emergency health care needs and understanding morbidity patterns may aid health administrators in resource allocation and planning of training needs $[16,17]$. Descriptive information about ED patients is scarce in Nepal. Surprisingly little is known about mortality after emergency care and studies in Nepal have reported hospital and ED mortality to one percent or less [18-20]. Mortality after ED visit is usually not documented, although discharge to home should not be regarded as a completion of patient management [21].

To add knowledge in this area, we aimed to describe 1) characteristics of adult ED patients across presenting complaints (PCs) in a hospital in Nepal; 2) mortality until 90 days after presentation and assess factors that are associated with mortality in this population. We took advantage of increasing access to mobile phones in Nepal and follow-up information was assessed by telephone interviews.

\section{MATERIALS AND METHODS}

\section{Study design and setting}

A prospective observational study was conducted in the ED of a non-government university hospital with 375 beds [22]. The hospital is located in semi-urban region in Dhulikhel, in Kavrepalanchok district 30 $\mathrm{km}$ northeast of Kathmandu. Kavrepalanchok district has a total population of nearly 400000 and $51 \%$ are female [23]. The median age in this region is 23 years, and $30 \%$ are $0-15$ years old. The corresponding figures for Nepal as a whole are: 23 years median age and 35\% are less than 20 years. The three main ethnic groups in the district are Brahmin/Chheti (36\%) followed by Janajati (51\%) and Dalit (7\%). The majority $(78 \%)$ of the population in this district use wood as a main type of cooking fuel.

\section{Data collection and participants}

Demographic and clinical information was prospectively registered in systematic emergency forms by ED nurses, paramedics and doctors, and was extracted into an electronic database by a research nurse (Appendix S1 in Online Supplementary Document). All adults (>16 years) presenting at the ED between September 2013 to December 2016 were included in the study. However, data collection was interrupted three times during the study period because of; failure to continue data collection (Sept 2014-Feb 2015), earthquakes (April 25-May 16 2015) and missing ED files (Sept and Nov 2016). Data from the earthquake period has been described previously [19].

\section{Variables}

Research nurses used the patients' home addresses to categorize their residence into rural (living outside a municipality) or urban (living inside a municipality). Ethnicity was categorized into four groups recognized by Nepali authorities; Brahmin and Chhetri, Janajati, Dalit, and others. Brahmin and Chhetri are generally considered as a group having a higher socioeconomic status and Dalit typically have a lower socioeconomic status [24].

Time of presentation at ED was categorized into; daytime (08-16 weekdays) and after working hours (1608) or holidays. ED disposition was categorized into; hospitalized, non-hospitalized or dead in the ED. 
Hospitalizations were further categorized: admitted to general wards, directly transferred to ICU (Intensive Care Unit) or OT (Operating Theatre), or referred to other hospitals from ED. Non-hospitalized patients were categorized into; doctor-initiated discharge or family-initiated discharge (FID).

\section{Presenting complaints classification}

The presenting complaints from the emergency forms were translated into "International Classification of Primary Care-2 (ICPC-2)" codes [25], and classified accordingly into nine main categories and each patient was assigned a primary PC category; self-harm, injuries, infections, unconsciousness, CVD (cardiovascular related complaints and diseases), respiratory complaints, OBGYN (obstetrics and gynecology), abdominal complaints and other complaints (Figure 1). Patients that had information on any NCDs at ED presentation in addition to the PC was given a NCD category; COPD (chronic obstructive pulmonary disease) or asthma, CVD and other NCDs (cancer, diabetes or chronic liver disease) in addition to the PC. The strategy for presenting complaint categorization and use of ICPC-2 codes is presented in the Annex S2 and Table S1 Online Supplementary Document.

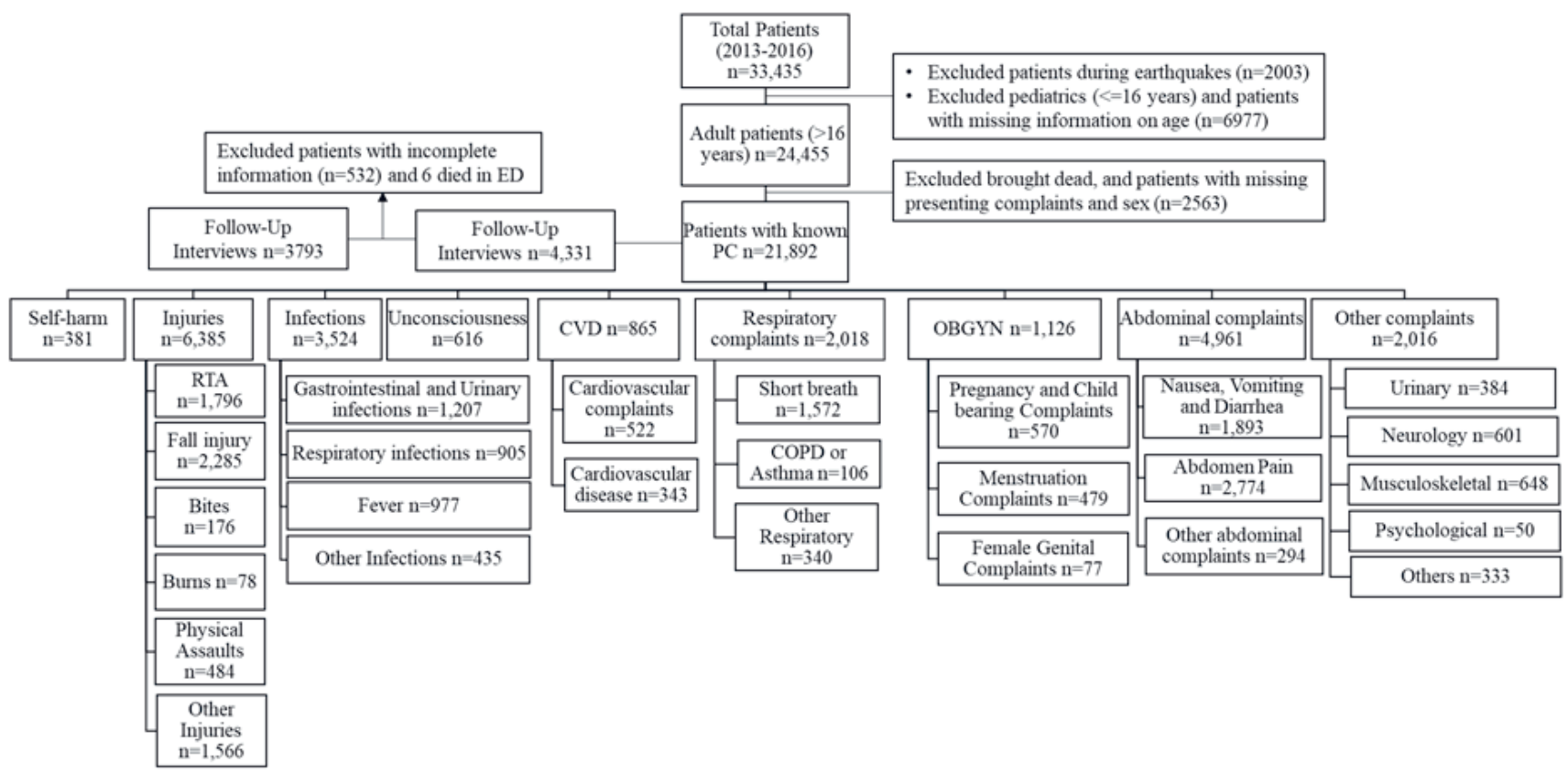

Figure 1. Flow diagram of cohort and distribution of presenting complaints. ED - emergency department, PC - presenting complaint, RTA - road traffic accidents, CVD-cardiovascular diseases or complaints, COPD - chronic obstructive pulmonary disease, OBGYN - obstetrics or gynecology.

\section{Follow-up interviews}

At ED disposition all patients were asked for consent to be telephone-interviewed at 90 days after initial presentation to the ED, and trained research nurses called and interviewed the patient or a family member (Annex S2 in Online Supplementary Document). The telephone interview was structured, and questions were about death or hospitalizations during last 90 days, and demographic information (literacy, occupation, number of family members living together, exposure level to smoke) (Annex S3 in Online Supplementary Document).

\section{Data analysis}

Descriptive data is presented by numbers and percentages. Associations between patient characteristics and mortality at 90 days were assessed by logistic regression models. Age and sex adjusted odds ratios (aORs) and unadjusted odds ratios (ORs) with 95\% confidence intervals (CIs) are presented. Data analyses were performed using STATA 13.1 (StataCorp LP, College Station Texas, USA). 


\section{Ethics}

The study was approved by the institutional ethical review committee of Kathmandu University School of Medical Sciences in Nepal (58/13) and the Regional Committee for Medical and Health Research Ethics in South East Norway (2014/1246). As this study is based on routinely collected pseudo anonymized patient information in the hospital, informed consent from the patients was not obtained in individuals, as approved by the local ethical committee. Verbal consent was taken for information on telephone numbers, and at the beginning of the telephone interviews.

\section{RESULTS}

\section{Patient characteristics}

During the study period, 33435 patients were enrolled. In total 21892 patients were included in the analysis (Figure 1). The most common presenting complaints were injuries (29\%), abdominal complaints (23\%), and infections (16\%) (Table 1). The median age of ED patients was 40 years (interquartile range IQR 26-60), and men and women were equally represented. Almost two thirds of the patients lived in rural areas.

One third (35\%) of the patients were hospitalized (Table 2). Of the 12101 (65\%) non-hospitalized, 10\% were FID (discharged by own or family's wish although hospitalization was required according to medical evaluation), and 51\% of FID were 17-45 years (Figure S1 in the Online Supplementary Document). The reported overall mortality in the emergency room was very low $(0.3 \%)$.

\section{Characteristics by presenting complaint categories}

Among injuries, 65\% were 17-45 years, and the majority (63\%) were men (Table 1). Falls from heights were the most common cause of injury (36\%) followed by traffic injuries (28\%) (Figure S2 in the Online Supplementary Document). Physical assaults accounted for 8\% of injured patients, and 36\% of these were women (Table 1). The majority of the patients (70\%) in injury group were discharged from ED without further hospitalization (Table 2).

Infections accounted for $16 \%$ of the ED population, and women were slightly overrepresented in this group (57\%) (Table 1). Respiratory and cardiovascular complaints accounted for 9\% and 4\% respectively and were similar distributed in both sexes. The proportion of patients with cardiovascular complaints that lived in urban areas was higher (46\%) compared to the total ED population (32\%). Patients with

Table 1. Baseline characteristics by categories of presenting complaints in 21,892 patients presenting to emergency department in Dhulikhel Hospital from Sept 2013- Dec 2016

\begin{tabular}{|c|c|c|c|c|c|c|c|c|c|c|}
\hline Characteristics & Total & InJURIES & $\begin{array}{l}\text { ABDoMINAL } \\
\text { COMPLAINTS }\end{array}$ & Imfections* ${ }^{*}$ & $\begin{array}{l}\text { RESPIRATORY } \\
\text { COMPLAINTS }\end{array}$ & OBGYN & CVD & $\begin{array}{l}\text { Uncon- } \\
\text { sciousness }\end{array}$ & SElF-haRM & $\begin{array}{c}\text { OtHER COM- } \\
\text { PLAINTS }\end{array}$ \\
\hline Total patients, n (\%) & 21892 & $6385(29)$ & $4961(23)$ & $3524(16)$ & $2018(9)$ & $1126(5)$ & $865(4)$ & $616(3)$ & $381(2)$ & $2016(9)$ \\
\hline Age, median (IQR) & $40(26-60)$ & $35(25-50)$ & $37(26-53)$ & $43(26-62)$ & $65(52-73)$ & $25(21-30)$ & $60(42-71)$ & $40(25-60)$ & $32(23-45)$ & $45(28-64)$ \\
\hline \multicolumn{11}{|l|}{ Age (years), n (\%): } \\
\hline $7-45$ & $12220(56)$ & $4144(65)$ & $3041(61)$ & $1802(51)$ & $327(16)$ & $1051(93)$ & $238(28)$ & $339(55)$ & $278(73)$ & $1000(50)$ \\
\hline $45-60$ & $4125(19)$ & $1256(20)$ & 949 (19) & $673(19)$ & 389 (19) & $61(6)$ & $193(22)$ & $122(20)$ & $80(21)$ & $402(20)$ \\
\hline$\geq 60$ & $5547(25)$ & $985(15)$ & $971(20)$ & $1049(30)$ & $1302(65)$ & $14(1)$ & $434(50)$ & $155(25)$ & $23(6)$ & $614(30)$ \\
\hline Female, n (\%) & $11365(52)$ & $2379(37)$ & $2809(57)$ & $2019(57)$ & $1037(51)$ & $1126(100)$ & $444(51)$ & $336(55)$ & $239(63)$ & $976(48)$ \\
\hline \multicolumn{11}{|c|}{ Patient location, $\mathbf{n}(\%)$ : } \\
\hline Rural & $13150(60)$ & $4153(65)$ & $2803(57)$ & 2062(58) & $1149(57)$ & $718(64)$ & $424(49)$ & $388(63)$ & $250(66)$ & $1203(60)$ \\
\hline Urban & $7030(32)$ & $1663(26)$ & $1833(37)$ & $1228(35)$ & $680(34)$ & $272(24)$ & $398(46)$ & $170(28)$ & $76(20)$ & $710(35)$ \\
\hline Information NA & $1712(8)$ & $569(9)$ & $325(6)$ & $234(7)$ & $189(9)$ & $136(12)$ & $43(5)$ & $58(9)$ & $55(14)$ & $103(5)$ \\
\hline \multicolumn{11}{|l|}{ Ethnicity, n (\%): } \\
\hline Brahmin and Chhetri & $9470(43)$ & $2627(41)$ & $2125(43)$ & $1625(46)$ & $907(45)$ & $517(46)$ & $372(43)$ & $261(42)$ & $135(36)$ & $901(45)$ \\
\hline Janajati & $10060(46)$ & $3001(47)$ & $2302(46)$ & $1566(45)$ & $930(46)$ & $466(41)$ & $412(48)$ & $277(45)$ & $183(48)$ & $923(46)$ \\
\hline Dalit & $1798(8)$ & $565(9)$ & $380(8)$ & $249(7)$ & $149(7)$ & $123(11)$ & $67(8)$ & $65(11)$ & $54(14)$ & $146(7)$ \\
\hline Other & $564(3)$ & $192(3)$ & $154(3)$ & $84(2)$ & $32(2)$ & $20(2)$ & $14(2)$ & $13(2)$ & $9(2)$ & $46(2)$ \\
\hline
\end{tabular}

OBGYN - obstetrics or gynecology, CVD - cardiovascular diseases or complaints, IQR - inter-quartile range, NA - not available

*Infections and fever.

†Other complaints included musculoskeletal, neurology, urinary, psychology and other general complaints (Table S1 in Online Supplementary Document). 


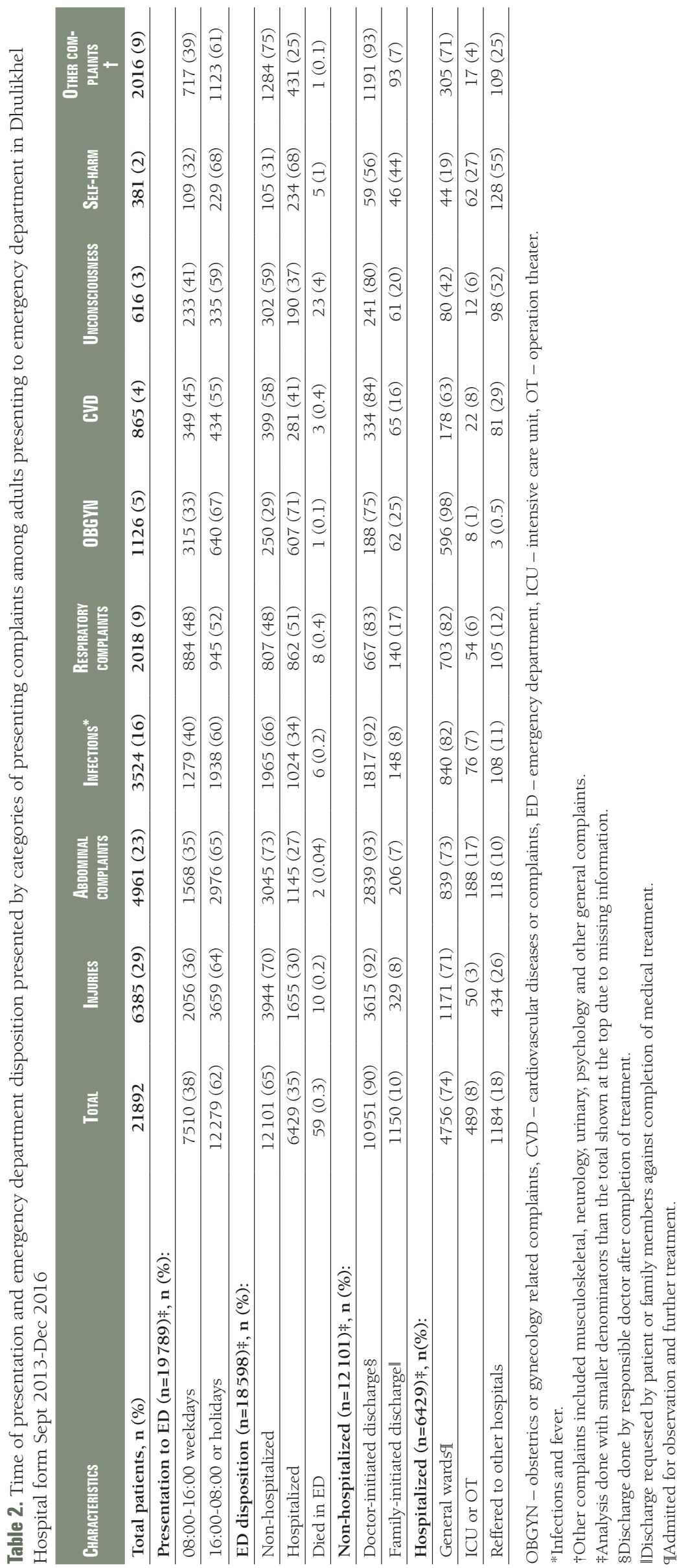

respiratory and cardiovascular complaints had higher hospitalization rates $51 \%$ and $41 \%$ respectively) than the average for the ED population (35\%) (Table 2). Of the hospitalized patients with cardiovascular complaints, more than one in four were referred to other hospitals. The non-hospitalized patients with respiratory and cardiovascular complaints had higher FID rates (17\% and $16 \%$ respectively) compared to $10 \%$ in the ED population.

Self-harm was the main PC for 381 patients (Table 1). The most notable findings in this group were the relatively low age and that women were over- represented; the majority (73\%) of these patients were young (17-45 years) and the majority were women (63\%). The Dalit ethnic groups were overrepresented among self-harm patients (14\% versus $8 \%$ in the total ED population). The hospitalization rate was high (68\%) and 27\% needed ICU treatment. FID from emergency room was common (44\%) in this group (Table).

\section{0-days mortality}

Of the 21892 included patients, a total of 12540 household phone numbers were recorded in the patient registry. Of these 12540 patients, 4331 households (20\% of total) participated in the structured telephone interview at 90 days (Figure 1). Among the interviews, we had complete information on 3793 (88\%) patients and these were included in the further analysis. The patient demographic characteristics and presenting complaints in interviewed patients did, however, not meaningfully differ between those who were lost to follow-up (Figure 2, panel A and Figure 2, panel B).

Results for mortality at 90 days are presented in Table 3. The 90-days mortality in the cohort was $8 \%(n=309)$, and mortality was higher in men (9\%) compared to women $(7 \%)$. The mortality was much higher in the older age group ( $23 \%$ in $\geq 60$ years) compared to the younger groups ( $1 \%$ in $17-45$ years). Compared to infections ( $7 \%$ 90-days mortality), corresponding mortality for injuries was 3\% (aOR=0.6, 95\% $\mathrm{CI}=0.4-1.0)$, for cardiovascular complaints $23 \%(\mathrm{aOR}=2.5,95 \% \mathrm{CI}=1.5-4.1)$ and for respiratory complaints $25 \%$ (aOR $=2.4,95 \%$ $\mathrm{CI}=1.6-3.6)$. Patients who did not re-visit the hospital had higher mortality (10\%) compared to those who had a second vis- 
A

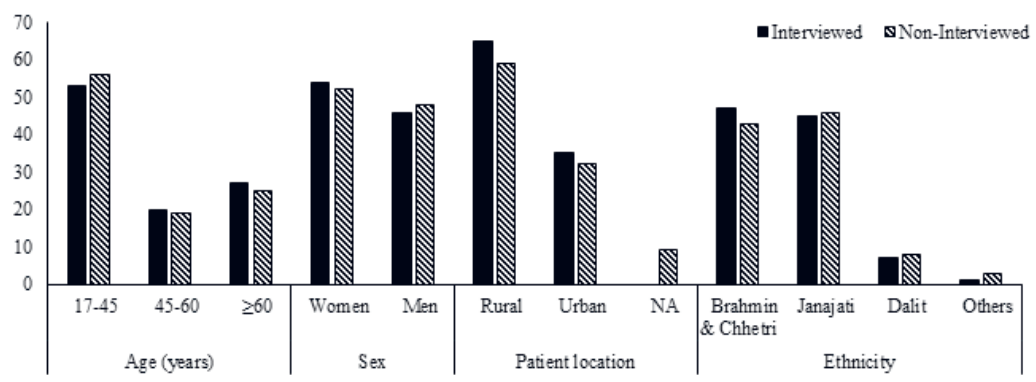

B

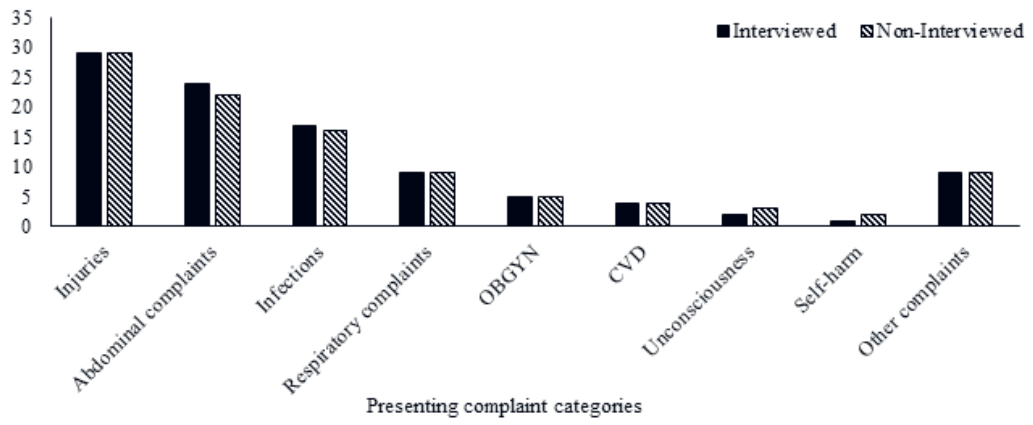

Figure 2. Panel A. Patient's characteristics in the interviewed patients compared with non-interviewed patients. NA - information not available. Panel B. Presenting complaint categories in the interviewed compared with non-interviewed patients. OBGYN - obstetrics and gynecology, CVD - cardiovascular diseases and complaints. it $(7 \%), \mathrm{aOR}=1.4(95 \% \mathrm{CI}=1.1-1.9)$. FID was strongly associated with mortality at 90 days $(\mathrm{aOR}=5.4,95 \% \mathrm{CI}=3.3-8.9)$ compared to doctor-initiated discharge. We assessed the associations of presenting complaints with 90 days mortality, taking NCDs into account. The results for these analyses show that mortality was particularly high for those with a NCD diagnosis, regardless of PC (COPD/asthma: 32\%, CVD: $21 \%$ and other NCDs: 24\%).

Associations between patient characteristics, based on follow-up interviews, and 90-days mortality are presented in Table 4. Just above half of the patients were illiterate $(53 \%)$ and the majority worked in own house or in agriculture (55\%). The proportion exposed to smoke (tobacco and/or traditional stoves) was high (67\%). There was no strong evidence of association between factors such as patient location, ethnicity, occupation or number of people in household and 90-days mortality.

We assessed evidence of interactions by sex for associations between demographic factors and 90-days mortality. Thus, results for

Table 3. Associations between presenting complaints and disposition characteristics, and 90 days mortality among 3793 patients interviewed by telephone after 90 days of emergency department visit

\begin{tabular}{|c|c|c|c|c|}
\hline Characteristics & TOTAL INTERVIEWED & 90 DAYS MORTALITY & UnadJusted OR (95\%CI) & AdJUSTED*OR (95\%CI) \\
\hline Presenting complaints, $\mathbf{n}(\%)$ & 3793 & $309(8)$ & & \\
\hline Injuries & $1085(29)$ & $34(3)$ & $0.4(0.3-0.7)$ & $0.6(0.4-1.0)$ \\
\hline Abdominal complaints & $910(24)$ & $58(6)$ & $0.9(0.6-1.3)$ & $1.2(0.8-1.8)$ \\
\hline Infections & $624(17)$ & $44(7)$ & Ref & Ref \\
\hline Respiratory complaints & $343(9)$ & $87(25)$ & $4.5(3.0-6.6)$ & $2.4(1.6-3.6)$ \\
\hline OBGYN & $200(5)$ & 0 & & \\
\hline CVD & $165(4)$ & $38(23)$ & $3.9(2.5-6.3)$ & $2.5(1.5-4.1)$ \\
\hline Unconsciousness & $71(2)$ & $10(14)$ & $2.1(1.0-4.5)$ & $2.2(1.0-4.8)$ \\
\hline Selfharm & $37(1)$ & 0 & & \\
\hline Other complaints & $358(9)$ & $38(11)$ & $1.6(1.0-2.5)$ & $1.5(0.9-2.4)$ \\
\hline \multicolumn{5}{|c|}{ Presention to ED $(\mathrm{n}=3561), \mathrm{n}(\%): \dagger$} \\
\hline 08:00-16:00 weekdays & $1527(43)$ & $163(11)$ & Ref & Ref \\
\hline 16:00-08:00 and holidays & $2034(57)$ & $123(6)$ & $0.5(0.4-0.7)$ & $0.7(0.5-0.9)$ \\
\hline \multicolumn{5}{|l|}{ Hospital revisit, n (\%): } \\
\hline Yes & $2486(66)$ & $184(7)$ & Ref & Ref \\
\hline No & $1307(34)$ & $125(10)$ & $1.3(1.0-1.7)$ & $1.4(1.1-1.9)$ \\
\hline \multicolumn{5}{|c|}{ ED disposition $(\mathrm{n}=3223), \mathrm{n}(\%): \dagger$} \\
\hline Non-hospitalized & $1948(60)$ & $84(4)$ & Ref & Ref \\
\hline Hospitalized & $1275(40)$ & $159(12)$ & $3.2(2.4-4.2)$ & $2.5(1.9-3.3)$ \\
\hline \multicolumn{5}{|c|}{ Non-hospitalized $(n=1948), n(\%): \dagger$} \\
\hline Doctor-initiated discharge $\ddagger$ & $1744(90)$ & $50(3)$ & Ref & Ref \\
\hline Family-initiated discharge§ & $204(10)$ & $34(17)$ & $6.8(4.3-10-8)$ & $5.4(3.3-8.9)$ \\
\hline \multicolumn{5}{|l|}{ Hospitalized $(n=1275), \mathrm{n}(\%): \dagger$} \\
\hline General wards\| & $1037(81)$ & $122(12)$ & Ref & Ref \\
\hline ICU or OT & $103(8)$ & $6(6)$ & $0.5(0.2-1.1)$ & $0.5(0.2-1.3)$ \\
\hline Referred to other hospitals & $135(11)$ & $31(23)$ & $2.2(1.4-3.5)$ & $2.0(1.3-3.3)$ \\
\hline
\end{tabular}

CI - confidence interval, OR - odds ratio, OBGYN - obstetrics or gynecology related complaints, CVD - cardiovascular diseases or complaints, ED emergency department, ICU - intensive care unit, OT - operation theater

*Adjusted for sex and age in category.

$\dagger$ Analysis done with smaller denominators than the total shown at the top.

¥Discharge done by responsible doctor after completion of treatment.

$\S$ Discharge requested by patient or family members against completion of medical treatment.

\|Admitted for observation and further treatment. 
associations between demographic factors and 90-days mortality are presented separately for men and women. In women, literacy was strongly associated with 90-days mortality (aOR for illiteracy=7.0, 95\% $\mathrm{CI}=2.1-23.6$ ) compared to literate group (Table 5). No such association was found in men (interaction

Table 4. Associations between demographic factors and 90 days mortality among 3793 patients interviewed by telephone after 90 days of emergency department visit

\begin{tabular}{|c|c|c|c|c|c|c|c|c|}
\hline \multirow{3}{*}{ Characteristics } & \multirow{3}{*}{$\begin{array}{c}\text { Total } \\
\text { INTERVIEWED }\end{array}$} & \multirow{3}{*}{90 DAYS MORTALITY } & \multicolumn{3}{|c|}{ WoMEN ( $=2038)$} & \multicolumn{3}{|c|}{$\operatorname{MeN}(N=1755)$} \\
\hline & & & \multirow{2}{*}{$\begin{array}{l}90 \text { DAYS } \\
\text { MORTALITY }\end{array}$} & Unadjusted & Adjusted* & \multirow{2}{*}{$\begin{array}{l}90 \text { days } \\
\text { mortality }\end{array}$} & \multirow{2}{*}{$\begin{array}{l}\text { Unadjusted } \\
\text { OR 95\%CI }\end{array}$} & \multirow{2}{*}{$\begin{array}{l}\text { Adjusted* } \\
\text { OR 95\%CI }\end{array}$} \\
\hline & & & & OR 95\% CI & OR 95\%CI & & & \\
\hline Total, n(\%) & 3793 & $309(8)$ & $143(7)$ & & & $166(9)$ & & \\
\hline \multicolumn{9}{|l|}{ Age, (years), n (\%): } \\
\hline $17-45$ & $2022(53)$ & $28(1)$ & $8(1)$ & $0.1(0.04-0.2)$ & & $20(2)$ & $0.5(0.3-1.0)$ & \\
\hline $45-60$ & $755(20)$ & $43(6)$ & $27(7)$ & Ref & & $16(4)$ & Ref & \\
\hline$\geq 60$ & $1016(27)$ & $238(23)$ & $108(21)$ & $3.5(2.3-5.5)$ & & $130(26)$ & $8.0(4.5-13.3)$ & \\
\hline \multicolumn{9}{|l|}{ Patient location, n (\%): } \\
\hline Urban & $1338(35)$ & $105(8)$ & $53(7)$ & Ref & Ref & $52(9)$ & Ref & Ref \\
\hline Rural & $2455(65)$ & $204(8)$ & $90(7)$ & $1.0(0.7-1.4)$ & $1.0(0.7-1.4)$ & $114(10)$ & $1.1(0.8-1.6)$ & $1.2(0.8-1.7)$ \\
\hline \multicolumn{9}{|l|}{ Ethnicity, n (\%) } \\
\hline Brahmin and Chhetri & $1772(47)$ & $143(8)$ & $68(7)$ & Ref & Ref & $75(9)$ & Ref & Ref \\
\hline Janajati & $1690(45)$ & $140(8)$ & $63(7)$ & $1.0(0.7-1.4)$ & $0.9(0.6-1.3)$ & $77(10)$ & $1.0(0.8-1.4)$ & $1.1(0.8-1.6)$ \\
\hline Dalit & $281(7)$ & $24(9)$ & $12(8)$ & $1.1(0.6-2.1)$ & $1.3(0.7-2.7)$ & $12(9)$ & $1.0(0.5-1.9)$ & $1.6(0.8-3.2)$ \\
\hline Others & $50(1)$ & $2(4)$ & 0 & & & $2(6)$ & $0.6(0.1-2.8)$ & $1.5(0.3-7.1)$ \\
\hline \multicolumn{9}{|l|}{ Education, n (\%): } \\
\hline Literate & $1765(47)$ & $48(3)$ & $3(0.4)$ & Ref & Ref & $45(5)$ & Ref & Ref \\
\hline Illiterate† & $2028(53)$ & $261(13)$ & $140(11)$ & $33.9(10.8-106.9)$ & $7.0(2.1-23.6)$ & $121(15)$ & $3.7(2.6-5.3)$ & $1.0(0.7-1.6)$ \\
\hline \multicolumn{9}{|l|}{ Occupation, n (\%): } \\
\hline Paid job or business & $933(25)$ & $56(6)$ & $10(3)$ & Ref & Ref & $46(7)$ & Ref & Ref \\
\hline Agriculture or housewives & $2101(55)$ & $210(10)$ & $110(8)$ & $2.3(1.2-4.5)$ & $0.9(0.4-1.9)$ & $100(15)$ & $2.3(1.6-3.2)$ & $0.7(0.4-1.0)$ \\
\hline Student & $264(7)$ & $1(0.4)$ & $1(1)$ & $0.2(0.03-1.9)$ & $1.2(0.1-10.0)$ & 0 & & \\
\hline Elderly or sick $\ddagger$ & $495(13)$ & $42(8)$ & $22(11)$ & $3.3(1.5-7.1)$ & $0.5(0.2-1.1)$ & $20(7)$ & $1.0(0.6-1.7)$ & $0.2(0.1-0.3)$ \\
\hline \multicolumn{9}{|c|}{ No. of members in house, $n(\%)$ : } \\
\hline$\leq 5$ members & $2169(57)$ & $158(7)$ & $71(6)$ & Ref & Ref & $87(9)$ & Ref & Ref \\
\hline$>5$ members & $1624(43)$ & $151(9)$ & $72(8)$ & $1.4(1.0-2.0)$ & $0.9(0.7-1.4)$ & $79(11)$ & $1.3(0.9-1.7)$ & $0.8(0.6-1.2)$ \\
\hline \multicolumn{9}{|c|}{ Exposure to smoke, n (\%): } \\
\hline None & $1254(33)$ & $72(6)$ & $31(4)$ & Ref & Ref & $41(8)$ & Ref & Ref \\
\hline Traditional stove only§ & $1511(40)$ & $109(7)$ & $52(6)$ & $1.5(0.9-2.3)$ & $1.2(0.7-1.9)$ & $57(9)$ & $1.1(0.7-1.7)$ & $0.9(0.6-1.4)$ \\
\hline Tobacco only & $559(15)$ & $62(11)$ & $26(10)$ & $2.4(1.4-4.1)$ & $1.8(1.0-3.2)$ & $36(13)$ & $1.7(1.0-2.7)$ & $1.5(0.9-2.6)$ \\
\hline $\begin{array}{l}\text { Tobacco and } \\
\text { traditional stovell }\end{array}$ & $469(12)$ & $66(14)$ & $34(19)$ & $5.2(3.1-8.8)$ & $2.8(1.6-4.9)$ & $32(11)$ & $1.5(0.9-2.4)$ & $1.4(0.8-2.4)$ \\
\hline
\end{tabular}

OR - odds ratio, $\mathrm{CI}$ - confidence interval

*Adjusted for age in category.

$\dagger$ Interaction $P<0.0001$

¥Cannot work because of being old or sick.

$\S$ Traditional stoves do not have proper smoke outlet.

IInteraction $P=0.09$.

Table 5. Associations between presenting complaints, including NCD information at presentation, and 90 days mortality among 3793 patients interviewed by telephone after 90 days of emergency department visit

\begin{tabular}{|c|c|c|c|c|}
\hline Paesenting complaints and NCD information, n (\%) & TOTAL INTERVIEWED & 90 DAYS MORTALITY & UnadJusted OR (95\%CI) & AdJusted* OR (95\%CI) \\
\hline Total & 3793 & $309(8)$ & & \\
\hline -Injuries, no NCD $\dagger$ & $1048(28)$ & $24(2)$ & $0.5(0.3-0.8)$ & $0.6(0.3-1.0)$ \\
\hline -Infections, no NCD $\dagger$ & $650(17)$ & $30(5)$ & Ref & Ref \\
\hline -Other PCs, no NCD* $\dagger$ & $1583(42)$ & $119(8)$ & $1.7(1.1-2.5)$ & $1.7(1.1-2.7)$ \\
\hline -Any PC and COPD/Asthma & $214(6)$ & $69(32)$ & $9.8(6.2-15.7)$ & $3.7(2.3-6.0)$ \\
\hline -Any PC and CVD & $161(4)$ & $34(21)$ & $5.5(3.3-9.4)$ & $2.7(1.6-4.8)$ \\
\hline -Any PC and other NCDs & $137(4)$ & $33(24)$ & $6.6(3.8-11.2)$ & $4.5(2.5-7.9)$ \\
\hline \multicolumn{5}{|c|}{$\begin{array}{l}\text { NCD - non communicable disease, CI - confidence interval, OR - odds ratio, PC - presenting complaints, COPD - chronic ob- } \\
\text { structive pulmonary disease, CVD - cardiovascular diseases. Other PCs - includes other presenting complaints such as; self-harm, } \\
\text { obstetrics and gynecology, abdominal complaints, urinary, neurology, musculoskeletal and psychological. Other NCDs - include } \\
\text { liver disease }(n=81) \text {, cancer }(n=19) \text { and diabetes }(n=37) \text {. } \\
\text { *Adjusted for sex and age in category. } \\
\text { †Does not include NCD. }\end{array}$} \\
\hline
\end{tabular}


$P<0.001)$. In women, the association between exposure to smoke and 90-days mortality was strong: aORs for mortality in women exposed to traditional cooking stoves, tobacco smoking, and tobacco plus traditional cooking stove compared to no smoking exposure were 1.2 (95\% CI=0.7-1.9), 1.8 (95\% CI=1.0$3.2)$ and 2.8 (95\% CI=1.6-4.9) respectively.

\section{DISCUSSION}

\section{Population}

Our study is in line with a systematic review in LMICs [6] and studies from Nepal [26] and Cambodia [27], showing that the majority of emergency patients are young adults. Injury was the main presenting complaint followed by abdominal complaints and infections, similar to reports from other LMICs [28,29].

Hospitalization rate from ED in the present study was lower (29\%) than reported in other studies from Cambodia (60\%) [27] and Pakistan (36\%) [30]. This is probably due to different health care systems in these countries, and the fact that the study hospital receives unselected patients. Direct transfers from ED to ICU or OT were less frequent (8\%) than reported in Pakistan (13\%) [30]. However, these proportions do not depend only on severity, but also on the capacity of ICU and OT in the hospital. These observations indicate important variations in practice, and may complement the findings from a systematic review and reports from Nepal and Pakistan that reported a need for specialty trained ED providers [6], patient management protocols [8], availability of essential emergency equipment and knowledge among providers [31].

The rate of FID was high (10\%). A study from India found this proportion to be (4\%) [32] and in that study the majority were female and majority reported financial reason for the discharge request [32]. Sex differences for FID were not observed in our study, but over 50\% were young (17-45 years), only onethird were $\geq 60$ years. Information on reasons for FID was not available for this study, but based on local knowledge, it is often related to financial reasons, or a wish to continue medication at home. Especially in the elderly and severely ill population, terminal care at home is often preferred. In a study from USA, delay in care and inadequate patient-provider communication was the reason for FID [33]. We observed a very high 90-days mortality among patients after FID, much higher than in a population-based study in Manitoba [34]. The high mortality in this group can be explained by the Nepalese culture favoring dying at home. However, further investigations are required to understand reasons for FID or leaving hospital against medical advice.

\section{Injuries}

Road traffic injuries in Sub-Saharan Africa and Southeast Asia have increased by 10-50\%, and are projected to be the sixth-leading cause of deaths and third-highest cause of DALYs in this region [4]. In Nepal, road traffic injury ranks 8th among the causes of premature deaths [35]. In the current study, the proportion of injury has increased compared to a report from the same hospital in 2013 [36]. We found fall injuries as the most common injury type, followed by traffic injuries. Young men were mostly affected by injuries, consistent with comparable settings [13,26,36-40]. The 90-days mortality in this group was $3 \%$, a very high number when taking into account that the most severely injured patients may never have reached hospital. These findings indicate a need to establish robust trauma services and underline the importance of strengthening the health response capacity and health infrastructure in the rural regions. Moreover, prevention of injuries should be a national priority, and is achievable as evidenced from other developed countries in the past decades that has reported significant decrease in traffic related deaths [41].

\section{Self-harm}

Although a relatively small proportion of ED patients, self-harm and suicide are increasingly recognized as a health problem in LICs, particularly in women. The maternal mortality and morbidity report from Nepal in 2008/09 had reported that suicide was the single leading cause of death among women of reproductive age (16\%) compared to maternal related issues (12\%) [42]. Suicide in Nepal is stigmatized and many could be reported as accidents. In the present study, more than two thirds of self-harm patients were women less than 45 years of age. In line with another study from Nepal [43], we found that these patients were seriously ill, and the majority were admitted to an ICU. These findings indicate that self-harm is a serious health problem especially among young women. Further studies and effective preventions are warranted. 


\section{Mortality}

Mortality by 90 days after emergency health care in the current study was more than 20-fold the ED mortality. The ED mortality in the current study was lower (0.3\%) than previously reported from Pakistan (1.3\%), and a systematic review in LMICs reported a median ED mortality of 1.8\% (IQR 0.2-5.1\%) [6,44].

Very little evidence exists on mortality after emergency care in LMIC's. To the best of our knowledge, only one study has previously attempted to assess mortality after emergency care. The study from a tertiary level Vietnamese hospital assessed 30-days mortality in two much smaller ED populations and reported mortality of $9.8 \%$ and $7.8 \%$, respectively [45]. However, that study is different from ours since they did not include trauma and surgical cases, and the cohorts were recruited from a selected population in three months periods not taking into account seasonal variations [45].

Patients with respiratory and cardiovascular complaints had particularly high mortality. Thus, nearly one in four patients with these complaints died within 90-days. This is much higher than reports from HICs. The 60-days mortality among patients with respiratory complaints in a Spanish study was 6.3\% [46]. Safwenberg and coworkers reported from a Swedish hospital that patients with cardiovascular complaints were at high risk for ten-year mortality (42\% for chest pain and $67 \%$ for stroke-like symptoms), and suggested that the ED complaints are equally important as diagnosis in predicting long-term mortality [17].

Many factors may contribute to the high post-discharge mortality that we observed. We suspect that patients in the present study presented to health care at a late stage of chronic diseases, since health services are unaffordable for many of these patients $[15,47]$. Typically, availability of long-term treatments for COPD and CVD patients is very low, and follow-up systems for chronically ill patients are underdeveloped $[15,48]$. Also, local systems and transport systems that can handle quick and adequate responses to acute illness are underdeveloped, and contribute to a high post-discharge mortality in these patients. These results suggest a need to develop post-discharge care systems that would likely reduce long-term mortality in emergency patients.

Interestingly, we found illiteracy independently associated with increased mortality at 90 days in women but not in men. Secondary analysis of 2011 Nepal Demographic and Health Survey reports that illiterate Nepalese women are less aware of health risks, and that could result in less health seeking behavior [49]. Further, a higher mortality was observed with increasing dose of smoke exposure in women but not in men. A high burden of chronic lung disease in Nepalese women has been reported earlier, one study reported that COPD was nearly half of the NCD burden in Nepal [14]. Another study reported that the prevalence and incidence of COPD in men was high, but corresponding mortality and DALYs were higher in women [50]. Nepalese women typically spend much time cooking and many are exposed to traditional cooking stoves affecting respiratory health and symptoms of respiratory problems are often long-standing without seeking health care [51,52].

\section{Strengths and limitations}

This is a single-center study, thus generalizations should be done with caution. However, the cohort comprised a large population from both rural and urban regions and the distribution of patient characteristics show that the patient population is highly representative for the region in respect to age, gender, geography and ethnicity. Also, the long data collection period is a strength; the study includes data from a three year period, covering possible seasonal variations. However, it is a limitation that the study had a low follow-up rate for the 90 days telephone interviews. For the interviews, the results should interpreted with caution, although we show that those lost to follow-up have similar characteristics and PCs. We cannot rule out the possibility of selection bias in the interviewed patients, leading to possible underestimation of mortality and a higher follow-up in healthier and more resourceful families. Patients who did not provide their telephone number were not interviewed and these patients might not have had a phone due to economic conditions, and could also be frailer than the ones available for interviews. Also, it is possible that those who were called and did not answer were more likely to have died.

Classification of presenting complaints was performed using a hierarchy approach which may result in an underestimation of frequency of complaints lower in the hierarchy (e.g. if a patient had pneumonia and COPD then he/she would be allocated to the infection category). 


\section{CONCLUSIONS}

The study revealed that nearly one in ten died within 90-days of emergency care. However, follow-up rates were low and findings suggest a need for replication of post-discharge mortality studies with adequate systems that limit loss to follow-up. These studies should be performed as multi-center studies and include information on local health care systems that may affect post-discharge mortality. It will be important to study factors that affect post-discharge mortality, such as availability of follow-up systems, transportation and affordable medication. We argue that post-discharge mortality is a particularly important indicator on quality of care in low-resource settings, where primary care health systems are limited, and transportation and economic issues may halter adequate follow-up and treatment for complications or chronic diseases.

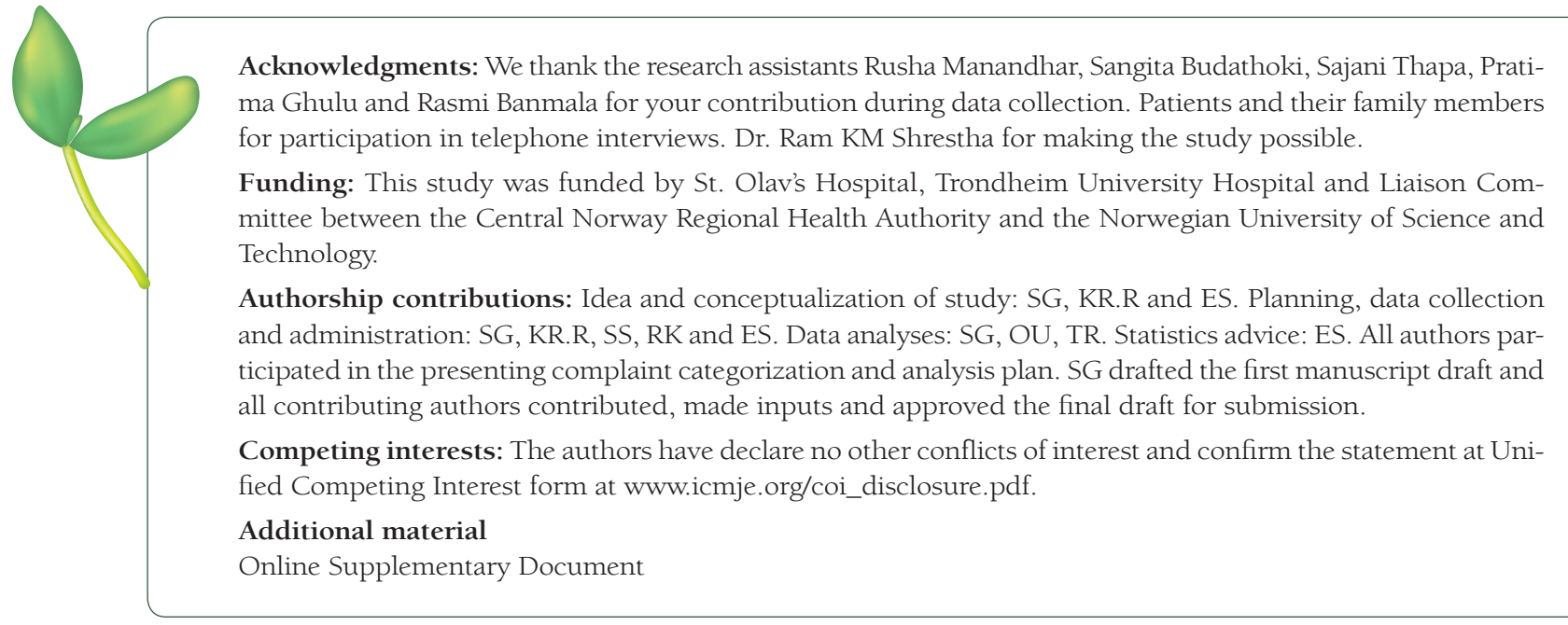

1 Kobusingye OC, Hyder AA, Bishai D, Joshipura M, Hicks ER, Mock C. Disease Control Priorities in Developing Countries 2nd edition. New York: Oxford University Press; 2006.

2 World Health Organization. Emergency care systems, 2018. Available: http://www.who.int/emergencycare/en/. Assessed: 16 March 2018.

3 Chang CY, Abujaber S, Reynolds TA, Camargo CA Jr, Obermeyer Z. Burden of emergency conditions and emergency care usage: new estimates from 40 countries. Emerg Med J. 2016;33:794-800. Medline:27334758 doi:10.1136/ emermed-2016-205709

4 Hsia R, Razzak J, Tsai AC, Hirshon JM. Placing Emergency Care on the Global Agenda. Ann Emerg Med. 2010;56:1429. Medline:20138398 doi:10.1016/j.annemergmed.2010.01.013

5 Moresky RT, Bisanzo M, Rubenstein BL, Hubbard SJ, Cohen H, Ouyang H, et al. A research agenda for acute care services delivery in low- and middle-income countries. Acad Emerg Med. 2013;20:1264-71. Medline:24283791 doi:10.1111/ acem.12259

6 Obermeyer Z, Abujaber S, Makar M, Stoll S, Kayden SR, Wallis LA, et al. Emergency care in 59 low- and middle-income countries: a systematic review. Bull World Health Organ. 2015;93:577-586G. Medline:26478615 doi:10.2471/ BLT.14.148338

7 Abujaber S, Chang CY, Reynolds TA, Mowafi H, Obermeyer Z. Developing metrics for emergency care research in lowand middle-income countries. Afr J Emerg Med. 2016;6:116-24. Medline:30456077 doi:10.1016/j.afjem.2016.06.003

8 Pandey NR. Emergency medicine in Nepal: present practice and direction for future. Int J Emerg Med. 2016;9:20. Medline:27416937 doi:10.1186/s12245-016-0118-3

9 World Health Organization. Health System in Nepal: Challenges and Strategic Options, 2007. Available: https://apps. who.int/iris/handle/10665/205257. Accessed: 5 May 2018.

10 Dulal P, Khadka SB. Victims of road traffic crashes attending the emergency department of Kathmandu Medical College Teaching Hospital. Kathmandu Univ Med J (KUMJ). 2004;2:301-6. Medline:16388241

11 Murdoch DR, Woods CW, Zimmerman MD, Dull PM, Belbase RH, Keenan AJ, et al. The etiology of febrile illness in adults presenting to Patan hospital in Kathmandu, Nepal. Am J Trop Med Hyg. 2004;70:670-5. Medline:15211012 doi:10.4269/ajtmh.2004.70.670

12 B.P Koirala Institute of Health Sciences. Emergency Hospital Services. Available: http://www.bpkihs.edu/?hospital-services.html. Accessed: 17 March 2018. 
13 Karkee R, Lee AH. Epidemiology of road traffic injuries in Nepal, 2001-2013: systematic review and secondary data analysis. BMJ Open. 2016;6:e010757. Medline:27084283 doi:10.1136/bmjopen-2015-010757

14 Bhandari GP, Angdembe MR, Dhimal M, Neupane S, Bhusal C. State of non-communicable diseases in Nepal. BMC Public Health. 2014;14:23. Medline:24405646 doi:10.1186/1471-2458-14-23

15 The Nepal NCDI Poverty Commission. The Nepal NCDI Poverty Commission; An Equity Initiative to Address Noncommunicable Diseases and Injuries, National Report, 2018. Available: http://www.ncdipoverty.org/nepal-report/. Accessed: 12 Nov 2018).

16 Mowafi H, Dworkis D, Bisanzo M, Hansoti B, Seidenberg P, Obermeyer Z, et al. Making recording and analysis of chief complaint a priority for global emergency care research in low-income countries. Acad Emerg Med. 2013;20:1241-5. Medline:24283813 doi:10.1111/acem.12262

17 Safwenberg U, Terent A, Lind L. Differences in long-term mortality for different emergency department presenting complaints. Acad Emerg Med. 2008;15:9-16. Medline:18211307 doi:10.1111/j.1553-2712.2007.00004.x

18 Karki RK. Mortality patterns among hospital deaths. Kathmandu Univ Med J (KUMJ). 2016;14:65-8. Medline:27892444

19 Giri S, Risnes K, Uleberg O, Rogne T, Shrestha SK, Nygaard OP, et al. Impact of 2015 earthquakes on a local hospital in Nepal: A prospective hospital-based study. PLoS One. 2018;13:e0192076. Medline:29394265 doi:10.1371/journal. pone.0192076

20 Bharati U, Shrestha S. Mortality in Emergency Department of Nepal Medical College Teaching Hospital, a tertiary care centre in Kathmandu, Nepal. J Inst Med. 2017;39:94-8.

21 Couturier B, Carrat F, Hejblum G. A systematic review on the effect of the organisation of hospital discharge on patient health outcomes. BMJ Open. 2016;6:e012287. Medline:28003282 doi:10.1136/bmjopen-2016-012287

22 Dhulikhel Hospital. Dhulikhel Hospital Kathmandu University Hospital, Nepal. Available: http://www.dhulikhelhospital.org. Accessed: 1 Jan 2018.

23 Government of Nepal. National Population and Housing Census 2011, National Planning Commission, Central Bureau of Statistics 2012. Available: https://unstats.un.org/unsd/demographic/sources/census/wphc/Nepal/Nepal-Census-2011Voll.pdf. Accessed: 3 March 2019.

24 Bennett L, Dahal DR, Govindasamy P. Caste, Ethnic and Regional Identity in Nepal Further Analysis of the 2006 Nepal Demographic and Health Survey, USAID, 2008. Available: http://pdf.usaid.gov/pdf_docs/Pnadm638.pdf. Accessed: 23 Feb 2017.

25 World Organization of Family Doctors. International Classification of Primary Care (ICPC): Wonca International Classification Committee, 2017. Available: www.globalfamilydoctor.com. Accessed: 25 Aug 2017.

26 Basnet B, Bhandari R, Moore M. Initial resuscitation for Australasian Triage Scale 2 patients in a Nepalese emergency department. Emerg Med Australas. 2012;24:430-4. Medline:22862761 doi:10.1111/j.1742-6723.2012.01554.x

27 Yan LD, Mahadevan SV, Yore M, Pirrotta EA, Woods J, Somontha K, et al. An observational study of adults seeking emergency care in Cambodia. Bull World Health Organ. 2015;93:84-92. Medline:25883401 doi:10.2471/BLT.14.143917

28 Myers JG, Hunold KM, Ekernas K, Wangara A, Maingi A, Mutiso V, et al. Patient characteristics of the Accident and Emergency Department of Kenyatta National Hospital, Nairobi, Kenya: a cross-sectional, prospective analysis. BMJ Open. 2017;7:e014974. Medline:29025826 doi:10.1136/bmjopen-2016-014974

29 Hodkinson PW, Wallis LA. Cross-sectional survey of patients presenting to a South African urban emergency centre. Emerg Med J. 2009;26:635-40. Medline:19700577 doi:10.1136/emj.2008.063362

30 Khan BA, Shakeel N, Siddiqui EU, Kazi G, Khan IQ, Khursheed M, et al. Impact of delay in admission on the outcome of critically ill patients presenting to the emergency department of a tertiary care hospital from low income country. J Pak Med Assoc. 2016;66:509-16. Medline:27183926

31 Razzak JA, Baqir SM, Khan UR, Heller D, Bhatti J, Hyder AA. Emergency and trauma care in Pakistan: a cross-sectional study of healthcare levels. Emerg Med J. 2015;32:207-13. Medline:24157684 doi:10.1136/emermed-2013-202590

32 Naderi S, Acerra JR, Bailey K, Mukherji P, Taraphdar T, Mukherjee T, et al. Patients in a private hospital in India leave the emergency department against medical advice for financial reasons. Int J Emerg Med. 2014;7:13. Medline:24568343 doi:10.1186/1865-1380-7-13

33 Southern WN, Nahvi S, Arnsten JH. Increased risk of mortality and readmission among patients discharged against medical advice. Am J Med. 2012;125:594-602. Medline:22513194 doi:10.1016/j.amjmed.2011.12.017

34 Garland A, Ramsey CD, Fransoo R, Olafson K, Chateau D, Yogendran M, et al. Rates of readmission and death associated with leaving hospital against medical advice: a population-based study. CMAJ. 2013;185:1207-14. Medline:23979869 doi:10.1503/cmaj.130029

35 Institute for Health Metrics and Evaluation. Global Burden of disease, Nepal country profile, University of Washington 2018. Available: http://www.healthdata.org/nepal. Accessed 23 May 2018.

36 Shrestha R, Shrestha SK, Kayastha SR, Parajuli N, Dhoju D, Shrestha D. A comparative study on epidemiology, spectrum and outcome analysis of physical trauma cases presenting to emergency department of Dhulikhel Hospital, Kathmandu University Hospital and its outreach centers in rural area. Kathmandu Univ Med J (KUMJ). 2013;11:241-6. Medline:24442174 doi:10.3126/kumj.v1li3.12513

37 Gupta S, Gupta SK, Devkota S, Ranjit A, Swaroop M, Kushner AL, et al. Fall Injuries in Nepal: A Countrywide Population-based Survey. Ann Glob Health. 2015;81:487-94. Medline:26709280 doi:10.1016/j.aogh.2015.07.004

38 Bhatta S, Pant PR, Mytton J. Usefulness of hospital emergency department records to explore access to injury care in Nepal. Int J Emerg Med. 2016;9:21. Medline:27431800 doi:10.1186/s12245-016-0120-9

39 Oteng RA, Whiteside LK, Rominski SD, Amuasi JH, Carter PM, Donkor P, et al. Individual and Medical Characteristics of Adults Presenting to an Urban Emergency Department in Ghana. Ghana Med J. 2015;49:136-41. Medline:26693187 doi:10.4314/gmj.v49i3.2 
40 Sawe HR, Mfinanga JA, Mbaya KR, Koka PM, Kilindimo SS, Runyon MS, et al. Trauma burden in Tanzania: a one-day survey of all district and regional public hospitals. BMC Emerg Med. 2017;17:30. Medline:29029604 doi:10.1186/ s12873-017-0141-6

41 World Health Organization. World report on road traffic injury prevention, 2004. Available: http://www.who.int/violence_injury_prevention/publications/road_traffic/world_report/en/. Accessed 22 Aug 2018.

42 Suvedi BK, Pradhan A, Barnett S, Puri M, Chitrakar SR, Poudel P, et al. Nepal Maternal mortality and morbidity study 2008/2009: Summary of Preliminary Findings. Department of Health Services, 2009. Available: http://www.dpiap.org/ resources/pdf/nepal_maternal_mortality_2011_04_22.pdf. Accessed: 24 May 2018.

43 Paudyal BP. Poisoning: pattern and profile of admitted cases in a hospital in central Nepal. JNMA J Nepal Med Assoc. 2005;44:92-6. Medline:16554862

44 Rehmani R. Emergency section and overcrowding in a university hospital of Karachi, Pakistan. J Pak Med Assoc. 2004:54:233-7. Medline:15270179

45 Ha DT, Dang TQ, Tran NV, Pham TN, Nguyen ND, Nguyen TV. Development and validation of a prognostic model for predicting 30-day mortality risk in medical patients in emergency department. Sci Rep. 2017;7:46474. Medline:28401961 doi:10.1038/srep46474

46 Esteban C, Arostegui I, Garcia-Gutierrez S, Gonzalez N, Lafuente I, Bare M, et al. A decision tree to assess short-term mortality after an emergency department visit for an exacerbation of COPD: a cohort study. Respir Res. 2015;16:151. Medline:26695935 doi:10.1186/s12931-015-0313-4

47 Khanal S, Veerman L, Nissen L, Hollingworth S. Use of Healthcare Services by Patients with Non-Communicable Diseases in Nepal: A Qualitative Study with Healthcare Providers. J Clin Diagn Res. 2017;11:LC01-05. Medline:28764203 doi:10.7860/JCDR/2017/25021.9970

48 Checkley W, Ghannem H, Irazola V, Kimaiyo S, Levitt NS, Miranda JJ, et al. Management of NCD in low- and middle-income countries. Glob Heart. 2014;9:431-43. Medline:25592798 doi:10.1016/j.gheart.2014.11.003

49 Lam Y, Broaddus ET, Surkan PJ. Literacy and healthcare-seeking among women with low educational attainment: analysis of cross-sectional data from the 2011 Nepal Demographic and Health Survey. Int J Equity Health. 2013;12:95. Medline:24330671 doi:10.1186/1475-9276-12-95

50 Adhikari TB, Neupane D, Kallestrup P. Burden of COPD in Nepal. Int J Chron Obstruct Pulmon Dis. 2018;13:583-9. Medline:29445275 doi:10.2147/COPD.S154319

51 Po JYT, FitzGerald JM, Carlsten C. Respiratory disease associated with solid biomass fuel exposure in rural women and children: systematic review and meta-analysis. Thorax. 2011;66:232-9. Medline:21248322 doi:10.1136/thx.2010.147884

52 Smith-Sivertsen T, Diaz E, Pope D, Lie RT, Diaz A, McCracken J, et al. Effect of reducing indoor air pollution on women's respiratory symptoms and lung function: the RESPIRE Randomized Trial, Guatemala. Am J Epidemiol. 2009;170:21120. Medline:19443665 doi:10.1093/aje/kwp100 